\title{
On the record...
}

\section{Interview with Frikkie Venter, G4S Managing Director: Care and Justice Services}

\begin{abstract}
The Minister of Correctional Services recently made it known that the department is reviewing its policy on public-private partnerships (PPPs) for prisons. ${ }^{1}$ Currently there are two private prisons in South Africa, and the government has decided to build another four. However, for reasons that are not quite clear, there remains a great deal of controversy surrounding PPP prisons. One thing about which there is no disagreement, however, is that services at the existing two PPP prisons are of extremely high quality. Chandré Gould spoke to Frikkie Venter, G4S Managing Director in South Africa, about public-privatepartnerships for prisons.
\end{abstract}

Chandré Gould (CG): Many people may be nervous about handing the job of running prisons over to the private sector. After all, this has been something that the state has been responsible for in countries all around the world for hundreds of years. You would obviously say that there is a place for the private sector in the running of prisons. What would you argue is the advantage of private sector involvement in incarceration?

Frikkie Venter (FV): I think the first thing is that the concept is not strange in South Africa. In the 1800 s the private sector was involved in mine prisons.

In South Africa one of the main reasons for the recent private sector involvement in prisons was that the state needed an asset and didn't have the capital available for the building of new prisons. The state wanted an arrangement where they could pay off a prison, like you pay off a mortgage. The other reason was that basic rights were entrenched in the new constitution. The government wanted to ensure that rights were protected in new prisons and wanted to draw on best practices from Europe and abroad. The third reason was that it was expected that there would be a transfer of knowledge through this process. So the state prepared output specs for the contracts. Included in the contracts were penalties if the service provider did not deliver as required.
So at these PPP prisons service delivery is guaranteed through a punitive structure. Interestingly, there is no benefit for overperformance, which is strange for these types of contracts, but that is the way South Africa wanted to go at that time. The service delivery is monitored by about five correctional services officials, called controllers. These are DCS staff members, based at the PPP prisons, who see when you default on the contract and can report on that so that the operator incurs a financial penalty.

Perhaps the question should be: if the private sector can deliver the same service or outcome that government wants, cheaper than government can, using their business skills and efficiency to manage the process, why would we spend taxpayers' money on getting less for more? One needs to understand that the private sector has to be profitable. But at the same time we need to ensure the outcomes that government needs in terms of rehabilitation and so on. I think the Mangaung prison has shown that it can be done.

CG: If the private sector can do it, why can't the public service do it? Why can't the Department of Correctional Services deliver the same kind of service that you are delivering?

FV: When I was an employee of the Department of Correctional Services and they started talking 
about a PPP prison, I had exactly the same thought. 'We can do it ourselves, why do we need the private sector to do that?' What's quite clear is that a government is a political animal and you cannot move as quickly as you want on an operational level without getting the buy-in of the whole structure on top. So if you wanted to create for instance a C-Max prison, that will take ages to happen. The state can do it if it has the proper structures in place and if there's clear guidance on what it wants. But the private sector is more mindful of cost. It has the ability to be more innovative, not be bogged down by red tape, and the private sector can change its systems overnight to ensure service delivery. Government doesn't have that flexibility within its systems.

CG: You were in the Department of Correctional Services for 18 years. You didn't think that PPPs were necessarily a good idea. What brought about the change of heart?

FV: Towards the end of my career at corrections I was given the opportunity to open C-Max. Because that project was heavily supported by the Commissioner and the Minister, we were not bound by all the red tape of a normal project. So I got a feel for how quickly you can implement things if red tape is not there. At that time I was working directly for the Commissioner so could move quite quickly. Having had the experience of being able to deliver a project successfully and quickly (it took six weeks) it was difficult to go back to the normal state of affairs in Correctional Services where there was little opportunity to make an impact. I just couldn't do it anymore, since I knew I had it in me to make a difference, but felt restricted in executing what was necessary. When I was approached by private sector and given quite an open hand on how to establish a 3000 -bed facility, I jumped at that opportunity.

CG: Few of our readers will be fully informed about the current state of affairs in relation to the new PPP facilities. Briefly, there are currently two prisons in South Africa that are public-private partnerships. There are four more planned. What is the state of play? Where are we at?
FV: In terms of the two current projects, I think that status is quite clear. They are contracted to run the course of the existing 25-year contracts. In May last year the private sector was invited to submit bids for the remaining PPPs. We made submissions that are valid until November 2010. But the department has not opened the boxes containing those bids. This is partly due to the fact that the new Minister came in and she had to apply her mind to the concept of PPPs. She was followed by a new Commissioner, who had to have the same opportunity. So seemingly right now there are some reservations about the model and they are talking about a policy review. Whether that is being undertaken, or was undertaken, or whether it's in progress or not, we don't know. The fact is that we expect a briefing note from the department to tell us what stage we are at, and whether the DCS wants to change some of the specifications. This is a concern for us because some companies were shortlisted on being able to deliver specific outcomes. If I had been one of the companies that had not been shortlisted because, say I didn't have the custodial capability, and now custody is not part of the new specification, I would want the whole process to be opened up again. So there is some dilemma in terms of fair treatment, I think.

CG: So the DCS might have to reopen the tender if the specifications change significantly?

FV: If it changes significantly, they'll have to consider whether it can fit into the current process or not.

CG: So what, in essence, will be the effect of having a policy review? Quite aside from what the difference in policy might be ultimately. What is the impact of the minster's decision to revise the policy at this particular point?

FV: Any minister should have the opportunity or the leeway to change his or her mind. But what we have here is a situation that puts international investment at risk. The problem is essentially a lack of consistency that creates an uncertain environment, and which may result in international investors being cautious of South Africa as an investment destination. 
To date the private sector companies, including my company, have spent between R30 and R40 million on their bids. So when at the end of that bidding process, after you have spent your money, government comes back and they say that they wish to revert to a model that was debated three or four years ago, it is frustrating, and undermines investor confidence. What we want as the private sector is consistency and certainty. Keep in mind that we did not approach government with the idea of PPP prisons. The government approached the private sector and said, 'this is what we want and you can bid on it', and they provided specifications for what they wanted. It was on that basis that we prepared our bids. Now it looks like they want to change the specification again. If there are to be major changes to the specifications that require a redesign of the facilities, who is going to pay the architect? Can investors take that additional risk? If there is no solid commitment from government to move forward with PPPs, they cannot expect the private sector to continue making investments in the process. There needs to be clarity about what government wants and a long-term commitment to that in order to advance and create investor confidence.

\section{CG: The principle underlying policy change or} policy development should be that evidence suggests that a particular policy is the best way to solve the particular social problem. It seems to me that in a number of sectors at the moment we are seeing quite dramatic policy changes. For example, we've seen radical policy changes in the police that don't seem to be based on any evidence of what works or what could improve policing. Is there anything to suggest that there's new evidence, new information, new conditions that should give rise to a shift in policy in relation to PPP prisons, or is this shift, in your view, a response to political changes?

FV: I think it's difficult from where we sit to determine whether this is just a political change or whether it's a policy change. Nothing has happened in the last few years, as far as we are aware, that suggests that there should be a policy change. There were no changes to the Act [Correctional Services Act, No 111 of 1998]. The
Act that made provisions for the first PPP is still unchanged up to now. So clearly, legislative changes have not influenced this at all. What has changed is that in 2002 there was a lot of talk about the private sector being expensive (even though our calculations suggest that the private sector can run prisons at a lower cost than the state). Recent figures published by the Department of Finance suggest that the PPP prisons are costing less than correctional centres run by government, whilst the PPP Centres deliver higher levels of service. So it seems that 'value for money' or the concerns about cost have been the main reasons for concern by the state.

Yet there are glowing reports about service delivery at the private prisons being of a higher standard and more outcomes-based. One of the PPPs in fact contributes $40 \%$ of the total departmental targets in terms of key performance indicators set for rehabilitation programmes. In other words, centres accommodating $2,7 \%$ of the sentenced population contribute $40 \%$ towards delivering the DCS objectives. So quite clearly we are supporting them quite heavily to reach their target and we are doing more than logically would have been expected. So in terms of service delivery, in terms of legislation, in terms of money, there's no reason to doubt this process.

Whether the recidivism rate is lower or higher after offenders leave our facilities cannot be determined because currently the offenders stay with us for a period and then they move back to correctional services facilities. Whether they continue with the programmes they were involved in at our facilities, we don't know. Whether any programmes are available at the prisons they are transferred to, we don't know. We can't assess whether the programmes have a direct result that's positive, because prisoners have left us.

Having said that, as far as I can see there is no other reason than politics, that can drive policy review. Because what you have at the PPPs is costeffective, good, value-for-money service. Just look at the situation in relation to the new Kimberley prison. 
That facility was built by government, and what was reported to parliament in relation to the Medium Term Expenditure Framework, is that the cost of that facility was twice as high as the cost of prisons built through PPPs. At twice the price you would expect more services. That's not evident at this point in time. So it seems to me that the state is prepared to pay more for less.

CG: There's been concern expressed in the past about the fact that the PPPs create a situation in which there are vastly different services offered to the $2,7 \%$ of prisoners housed there as to the majority of prisoners in state institutions. So, for example, you have two PPP facilities where rehabilitation programmes are being offered because you are contractually required to do so, and not doing so would result in a financial penalty to you. However, the fact remains that we have two facilities housing some 6000 inmates receiving the best possible care, Ideally all inmates in South Africa should be receiving the same quality of care. And yet the majority of inmates in South Africa are likely receiving an inferior quality of care. How do we justify providing these kinds of services to a small number of inmates while the rest do not have access to the same quality services? And how do we address that? Is there a solution to this?

FV: I think this is a real human rights question. But I don't think it's a difficult one to answer. To say that about $95 \%$ of the sentenced population, that's the people that are not in the private sector, are not receiving services that are conducive to human rights, or up to scratch with international standards, and then to argue that the solution is to reduce all conditions to the lowest common denominator is the wrong way to go. We have to look at corrections holistically. We need to define what our focus is and where money should be spent. Last year, during the budget vote, we heard in parliament that most of the money for DCS goes towards security and less and less is going towards rehabilitation. We have seen the salary increases for civil servants. The portfolio committee has referred to the bloated management structures of the department. So there is a need to relook at how the money allocated to the department is spent. I think that's where the real answer lies.

The private sector is quite efficient because we run on business principles. We are there to make a profit. That means we have to deliver the services better than our competitors and achieve the required outcomes. For PPP prisons, not meeting the contractually specified outcomes can result in penalties that will reduce profits. We also have to run our facilities with fewer levels of management to reduce staff costs, without affecting supervision and support. The effect is that you run an efficient service. And if we can take that model and employ it in the other correctional centres, perhaps we will have learned effectively from the experience of PPPs. The point is that if through PPPs service delivery is optimised at a lower cost than that at which the state can deliver the same services, we owe it to taxpayers on the one hand, and to the person receiving that service, on the other, to do what's in their best interest.

That does not necessarily mean the private sector should run all prisons. The UK has an interesting approach. They had a private sector-run prison, and when after five years it was time to renew the contract both government and the private sector could tender to run the facility. In other words, the government department could tender to run their own facility. What happened is that the prison officers' association (the union) managed the bid for the department. Like the private sector, they had to tender to deliver particular outcomes set by the state. The state could then evaluate the bids in terms of cost-effectiveness. In that case the bid by the department was lower than the private sector. But there was a mechanism to hold the department to account for delivery of services. Suddenly there were measurable outcomes that you could track, that you couldn't before, and government officials couldn't use the excuse 'I don't have the budget' because they had set the price. Apparently the services improved dramatically in that prison because there were measurable outcomes. So whether it's government or the private sector providing the services doesn't really matter, as long as you have the required outcomes. 
In South Africa all prisons, private sector and government, fall under the same regulations, the same Act. But you see vast differences in service delivery. In the private sector you will find active supervision of staff and prisoners, which you won't always find in state prisons. And that's because the state is not outcomes-driven. So the question is how do we ensure outcomes? How do we manage facilities and monitor outcomes? I don't think that any government will say, for instance, outsource even $30 \%$ of an important function like corrections.

I think what we need to do is to say what type of offenders are we targeting, how we can ensure maximum impact in terms of rehabilitation. If the private sector is more effective in doing that, then let's give it to them to change the face of crime.

CG: In other words, what you're saying is that unless we apply the same kind of principles of accountability to government departments that we do in public-private partnerships, we're not going to be able to improve service delivery?

FV: Yes. It's about management.

CG: Do you have any final comments?

FV: I just think that people should understand why we have PPPs. The government says, 'We want a service. We can do it ourselves, but can the private sector do it cheaper and better?' If the private sector is cheaper and better, then the benefit goes to the taxpayer. There's more money available for something else, like improving the education system. Entering into a PPP is like buying a house: if you don't have the cash today to buy a house, you want to be able pay off your house over a period that means that you have money available to also feed your children. This is the rationale behind a PPP. The state wants the infrastructure, they can't pay for it now without diverting from other essential services, and therefore they utilise this mechanism of procurement to get the service. It's not that difficult to understand.

\section{NOTES}

1 Correspondence between Mr ZI Modise, Acting Chief Deputy Commissioner: Corrections, and Ms C Frank, Acting Executive Director of the ISS, dated 22 July 2010. 